\title{
ELOGIO DE LA ANTROPOLOGÍA HISTÓRICA: ENFOQUES, MÉTODOS Y APLICACIONES AL ESTUDIO DEL PODER Y DEL COLONIALISMO
}

Alexandre Coello de la Rosa y Josep Lluís Mateo Dieste, Zaragoza: Universitat Oberta de Catalunya / Universidad de Zaragoza, 2016, 330 pp.

La crítica postmoderna ha puesto en cuestión el trabajo de campo y la etnografía como fuentes directas al conocimiento de otras culturas, considerándolas meras expresiones textuales. El trabajo etnográfico de Bronislaw Malinoski, el llamado padre metodológico de la disciplina, ha sido comparado con el género de la literatura de viajes. Pero, como se ha puesto de manifiesto desde la historia de la antropología, que Malinoswki fuera considerado el padre metodológico de la disciplina estableciendo una frontera rígida con las investigaciones precedentes es parte del mito de origen construido a posteriori dentro de la propia disciplina. Las antropologías hegemónicas, en particular la anglosajona, crearon un antes y un después ficticio a partir de Malinowski. La institucionalización del paradigma malinowskiano en antropología, incluida la observación participante, fue la consecuencia de muchos factores, no todos ellos relacionados con el valor intrínseco del método en sí. ${ }^{1}$

Otra de las importantes epistemológicas, consecuencia del paradigma malinowskiano en antropología, fue la negación de la historia de su objeto/sujeto de estudio. Idea que, no obstante, compartió otro «padre» fundador de la antropología, Franz Boas, quien también se dedicó al estudio de la cultura, olvidando la historia de pueblos que fueron pensados como intrínsecamente «sin historia». De ese modo, la profesionalización de la disciplina en términos de trabajo de campo se fue consolidando mediante exclusiones tácticas y dislocaciones, en particular la exclusión de administradores coloniales y escritores de viajes, y la separación de la práctica etnográfica de sus contextos coloniales.

Con el libro Elogio de la antropología histórica: Enfoques, métodos y aplicaciones al estudio del poder y del colonialismo, Alexandre Coello de la Rosa y Josep Lluís Mateo

1. George W. Stocking, The Ethnographer's Magic and Other Essays in the History of Anthropology, Madison, Wis., London, The University of Wisconsin Press, 1992; Ivona Grgurinović, Anthropology and Travel: Practice and Text, Studia ethnologica Croatica, vol. 24, Etnološki zavod, Filozofski fakultet Sveučilišta u Zagrebu, 1993, pp. 47-49. 
Dieste nos introducen en este campo todavía poco definido, y no siempre reconocido dentro de la propia disciplina, de la antropología histórica. La antropología histórica rompe con esa separación artificial entre antropología e historia, abordando el pasado también como un problema etnográfico, así como igualmente el presente como un problema histórico.

El libro presenta la compleja, y no resuelta, relación entre antropología e historia, a partir del impacto de los profundos cambios políticos, económicos, filosóficos y sociales que acompañaron a la revolución industrial y que sentaron las bases de la filosofía de la historia de Karl Marx, Max Weber o Émile Durkheim. La antropología histórica, tal como la entienden los autores, incorpora a la historia en los fundamentos teóricos de la antropología y, en definitiva, de cualquier disciplina que se enfrente al reto de entender y explicar las sociedades humanas. Desde el punto de vista metodológico, e incorporando la crítica necesaria al archivo como instrumento del poder, la antropología histórica no excluye éste y otras fuentes documentales como documentos etnográficos, como serían la historia oral, las imágenes o los restos arqueológicos. Así, por ejemplo, los registros estadísticos, a pesar de ser instrumentos para el control de las poblaciones, no por ello dejan de ser herramientas valiosas para la investigación etnográfica pues nos aportan datos sobre la natalidad, mortalidad, nupcialidad, nacimientos, etc. Por otro lado, la literatura y las crónicas de viajes, a pesar del etnocentrismo y los prejuicios que contienen, también aportan información relevante para la antropología histórica que puede ser aprovechada con la perspectiva crítica necesaria y mediante su contraste con información procedente de diferentes tipos de fuentes. ${ }^{2}$

El libro está organizado en seis capítulos que abordan tanto los aspectos teóricos como las cuestiones metodológicas mencionadas. El primer capítulo está dedicado a esa imprecisa relación entre antropología e historia. Hace un repaso desde los clásicos en antropología social y cultural hasta autores más recientes que incorporaron un enfoque contextual o historicista en sus investigaciones. Coello y Mateo han optado por organizar el capítulo en trayectorias académicas nacionales, aunque sin duda el impacto que las tesis de muchos de estos autores han tenido para la disciplina trascienden dichas fronteras geopolíticas e intelectuales. Como novedad no solo presentan las trayectorias de las «antropologías hegemónicas» como la británica, francesa o estadounidense, sino también la de algunas «antropologías periféricas», en particular en el ámbito iberoamericano. Asimismo, no olvidan a aquellos autores clave que también decidieron incorporar la antropológica en sus investigaciones históricas y los espacios de diálogo entre antropólogos e historiadores que se fueron abriendo, así como las propuestas teóricas y metodológicas que fueron surgiendo.

El capítulo segundo está dedicado a una serie de antropólogos que, sin aparecer formalmente ubicados dentro de la antropología histórica, fueron pioneros de una forma de pensar y hacer antropología dentro de lo que Coello y Mateo entienden por antropología

2. Peter Hulme y Russell McDougall, «Introduction: in the margins of anthropology», en Writing, travel, and empire: in the margins of anthropology, 2007, pp. 1-16. 
histórica. Los elegidos son Julio Caro Baroja, Marshall Sahlins, Jean y John Comaroff, Eric Wolf y William Christian Jr. Todos ellos han abordado el estudio diacrónico de las sociedades humanas y pueden ser encuadrados en una teoría social más general.

El capítulo tercero aborda las epistemologías y métodos, donde los archivos, y no la observación participante, ocupan el lugar central. Señalan la influencia de la microhistoria de Carlo Ginzburg y los estudios sobre demonología y brujería europeas, interrogando los archivos inquisitoriales para reconstruir la conducta humana más allá de los sistemas prescriptivos y normativos. Y, en particular, Coello y Mateo centran su atención en los archivos coloniales, que ambos autores conocen bien por sus respectivas investigaciones en el ámbito americano y Asia-Pacífico (Coello) y magrebí (Mateo). La etnografía del archivo colonial, dicen los autores, «observa los documentos del poder para escudriñar el poder de los documentos y la dialéctica entre normatividad y praxis» (p. 129).

El capítulo cuarto está dedicado a los sistemas coloniales de poder y dominación, particularmente el europeo-occidental que emerge a principios de la Edad Moderna, aunque sin duda es aplicable a otros sistemas coloniales en otros contextos históricos y geopolíticos que podrían resultar muy interesantes desde una perspectiva comparativa. Fue fundamentalmente el colonialismo ibérico el que creó las Indias Occidentales y las Indias Orientales y definió y categorizó a sus habitantes. Así llegamos a la contundente crítica de Eric Wolf sobre los llamados «pueblos sin historia», cuando en realidad son negados como sujetos históricos en virtud de un sistema de relaciones de poder desiguales que les es impuesto y que va a alterar su destino. El trabajo de Sidney W. Mintz, Dulzura y poder. El lugar del azúcar en la historia moderna (1985), muestra la conexión entre lo que serían los procesos llamados globales y lo local, y rompe con la herencia antropológica que había ignorado el impacto del colonialismo en las sociedades «primitivas». Enseng Ho hace extensiva esta perspectiva no solo a los procesos políticos y a los sistemas económicos sino igualmente a la cuestión de los lazos de parentesco como creadores de pertenencia, mostrando que la globalización no es necesariamente un producto de los «occidentales». También en la relación entre los procesos globales y las respuestas locales señalan Coello y Mateo el trabajo de Benedict Anderson, Bajo tres banderas (2008), que se centra en las estrategias de los activistas mestizos acomodados en Filipinas y la relación entre el anarquismo y los movimientos anti-coloniales en el siglo XIX. Igualmente vamos a encontrar en este capítulo las llamadas «intersecciones coloniales» entre género, clase y «raza». Donde lo autores aluden, entre otros, al estudio pionero de Verena Stolcke sobre racismo y sexualidad en la Cuba colonial (siglos XVIII y XIX). Años después, Ann L. Stoler desarrolla un estudio similar, pero en otro contexto colonial, el de las Indias holandesas. Estas y otras investigaciones rompieron con la distinción entre lo público y lo privado, al mostrar como la sexualidad en el ámbito colonial constituía un motor político de las relaciones sociales. Otros trabajos en esta línea han abordado cuestiones como la violencia contra las mujeres o la ideología y prácticas eugenésicas imperiales. Finalmente, el capítulo aborda diversos enfoques diacrónicos de estudios sobre poder, resistencias y acomodaciones.

El capítulo quinto está dedicado a los sistemas de clasificación y exclusión social y sus argumentos legitimadores, particularmente a aquellos que emergen a partir del Rena- 
cimiento, la expansión colonial europea y la modernidad. Es decir, a partir del siglo XVI, que cuestionaron la hegemonía del saber de la tradición judeo-cristiana y su interpretación del mundo y los seres que lo habitan. También aborda la importancia de los archivos inquisitoriales para el estudio de grupos marginales, campo que ha sido muy fructífero tanto entre los antropólogos como entre los historiadores que han incorporado preguntas y miradas antropológicas, como el historiador francés de la tercera generación de los Annales, Le Roy Ladurie. La segunda parte del capítulo está dedicada al concepto de «raza», un concepto que jugó un papel fundamental en los imperios coloniales pero cuyos orígenes no han sido bien entendidos ni situados. Coello y Mateo hacen un repaso histórico sobre el concepto de «sangre» que poco a poco se irá vinculando al concepto de «raza» que, con la pseudociencia del XIX, acabará considerándose una característica «natural» de la persona, legitimando y perpetuando la desigualdad.

El sexto y último capítulo, titulado «Epílogo: el dilema del multiculturalismo», presenta una breve conclusión del libro y varias reflexiones de los autores. Retomando la cuestión de la arbitrariedad de las fronteras disciplinares, concluyen resumiendo los varios caminos presentados donde han confluido antropología e historia surgiendo varios modelos teóricos y metodológicos innovadores e inspiradores, que han sabido esquivar los «limitantes límites» de las «disciplinadas disciplinas» para abordar y entender problemas sociales: la escuela francesa de los Annales, la etnohistoria, la microhistoria, etc. No existe un monopolio de ningún enfoque teórico o metodológico ni de ninguna escuela nacional, y esta perspectiva abierta es quizás lo que ha impedido su consolidación académica, pero quizás también lo que le ha permitido mantener su frescura y apertura de miras. Evocando la metáfora del mestizaje, Coello y Dieste cuestionan que la antropología sea una disciplina híbrida. De hecho, como en el mestizaje, dicen los autores, la idea de mezcla disciplinar lejos de diluir la frontera, la reafirma, en este caso entre antropología e historia. En este epílogo Coello y Mateo abordan también uno de los resultados o consecuencias de ese encuentro (o desencuentro) colonial. Siguiendo a autores como Jean y John Comaroff, Roger M. Keesing y Jan Vansina reflexionan sobre las diferentes formas de contrapoder surgidas de ese encuentro. Así, volvemos a los sistemas de clasificación, siendo ahora la «cultura» la medida de todas las cosas. La emergencia del multiculturalismo, con su discurso relativista, que supuestamente protege y respecta a los «otros» culturalmente distintos, mientras que reafirma «nuestra» identidad cultural. Así, el multiculturalismo, lejos de borrar las diferencias, las reafirma en una especie de «pluralismo planificado» en palabras de Randi Gressgård (p. 267).

De este trabajo se desprende que entender las fuentes de la desigualdad y las tensiones sociales, la reproducción del poder, la naturaleza de las identidades sociopolíticas, de género, de clase, culturales, religiosas, los «sistemas» de parentesco, las cosmovisiones y ontologías, etc., debería ser el objetivo, y no el preocuparse por hacerlo desde la «pureza» de ninguna disciplina. Las propuestas metodológicas presentadas en este libro son una guía y una prueba de la artificial separación de antropología e historia. El camino a seguir, uno de los propuestos u otros desarrollados por otros autores no incluidos en este libro, o la elaboración de un nuevo modelo, dependerá de los diferentes problemas socia- 
les que deseemos investigar y del cómo vamos haciendo camino al andar, como dijo el poeta de Sevilla.

En fin, ni los autores han podido, ni yo puedo abarcar toda la riqueza de investigaciones en las que desde una perspectiva antropología histórica se han abordado problemas sociales relevantes y que Coello y Mateo han intentado sintetizar en este excelente trabajo que los autores han decidido llamar por su compromiso con esta mirada, Elogio de la Antropología histórica, perspectiva que, lamentablemente, sigue siendo marginal tanto para la antropología como para la historia. Muchos de los autores que aparecen en esta monografía son clásicos bien conocidos tanto en el ámbito disciplinar antropológico como el histórico, pero otros son autores menos conocidos que, lentamente, y seguramente sin pretenderlo, están contribuyendo a crear este corpus abierto y flexible de la antropología histórica. Resultando que, a pesar de su marginalidad, el número de antropólogos e historiadores que optan por una mirada más comprehensiva a los devenires humanos es mayor de lo que pueda parecer, y seguramente debe haber bastantes más autores «por descubrir». Coello y Mateo se han centrado fundamentalmente en aquellos autores que han tenido un impacto mayor en la antropología y en la historia, y en aquellos que han sido relevantes, además, para sus respectivas investigaciones en el ámbito hispano-americano y filipino y en norte de África. Espero que se animen y pronto tengamos el volumen II de Elogio a la antropología histórica.

Maite Ojeda-Mata

The Parkes Institute University of Southampton 